\title{
Dinamika Populasi Ikan Teri (Stolephorus sp) yang di Daratkan di Pasar Higienis Kota Ternate
}

\section{Faibun Hi Rauf ${ }^{1}$, Umar Tangke $^{2 \bowtie}$ dan Djabaluddin Namsa ${ }^{2}$}

${ }^{1}$ Alumni Prodi THP, Fakultas Pertanian, Universitas Muhammadiyah Maluku Utara. Ternate. Indonesia, Email : faibunhr@gmail.com

${ }^{2}$ Staf Pengajar Prodi THP Fakultas Pertanian, Universitas Muhammadiyah Maluku Utara. Ternate. Indonesia, Email : umbakhaka@gmail.com,djabaluddin@gmail.com

\footnotetext{
${ }^{{ }}$Korespondensi : Umar Tangke, Universitas Muhammadiyah Maluku Utara, Ternate, Indonesia, Email : umbakhaka@gmail.com
}

\begin{abstract}
ABSTRAK.
Eksploitasi ikan teri umumnya menggunakan alat tangkap bagan perahu yang memiliki tingkat produksinya tinggi dan sifatnya aktif, sehingga eksploitasi dengan alat tangkap ini sifatnya aktif dan tingkat produksi yang tinggi dan agar pemanfaatannya dapat berlangsung terus dan kelestariannya dapat terjaga, maka diperlukan eksplorasi yang baik terhadap sumberdaya ikan teri untuk meminimalkan permasalahan penurunan stok populasi. Penelitian ini dilaksanakan selama bulan Januari sampai Maret 2019 di Lab. PHP dengan sampel didapat dari pasar Higiensi Kota Ternate dengan tujuan untuk mengetahui informasi parameter dinamika populasi ikan teri di perairan Laut Maluku yang didaratkan di Pasar Higienis Kota Ternate dengan mengukur panjang dan berat ikan teri. Hasil penelitian didapat bahwa sumberdaya ikan teri yang didaratkan di Pasar Higienis Kota Ternate memiliki parameter populasi yang masih stabil diantaranya panjang maksimum (L国) adalah $71,9 \mathrm{~mm}$ dengan koefisien pertumbuhan (k) 0,26 per bulan, nilai t0 $-0,99$, nilai mortalitas total, alami, dan penangkapan masing-masing adalah 1,33; 1,12 dan 0,21 dan tingkat eksploitasi yang masih sangat rendah dengan hubungan panjang bobot bersifat alometrik positif.
\end{abstract}

\section{Keyword: Teri, Stelophorus, Parameter Populasi, Ternate}

\section{PENDAHULUAN}

\subsection{Latar Belakang}

Pemanfaatan sumberdaya perikanan di Provinsi Maluku Utara lebih didominasi oleh perikanan tangkap 82,46\% dengan jumlah potensi sumberdaya ikan yang dapat dimanfaatkan diperkirakan mencapai 150.997 ton/tahun untuk jenis ikan pelagis dan ikan domersal (DKP. Prov. Malut, 2016). Perairan Laut Maluku merupakan salah satu perairan yang sangat berperan dalam menyumbang produksi perikanan tangkap khususnya jenis ikan pelagis dan ikan demersal, dengan potensi perikanan tangkap diperkirakan sebesar 47.838,25 ton/tahun.

Ikan teri termasuk ke dalam ordo malacopterygi, family clupidae, jenis stoplehours sp. Ciri-ciri umum dari species ikan ini dapat mencapai panjang 40-145 mm, sisiknya tipis dan mudah terlepas, linea lateral terletak antara sirip dada dan sirip perut dan berwarna keperakan (Saanin, 2000). Ikan dari marga stolephours ini di kenal dengan nama teri, dimana sedikitnya ada beberapa jenis teri yang terdapat di Indonesia misalnya stolephours dan heterolobus, S. insularis, S. tri, S. baganensis, S. zolingeri, S. commersonii dan S. indicus. Menurut (Csirke, 2001), ikan teri (stolepshours spp) adalah ikan yang termasuk kedalam kelompok ikan pelagis kecil yang di duga merupakan salah satu sumberdaya perikanan paling melimpah di perairan Indonesia. Sama halnya dengan sumberdaya ikan lain, ikan teri merupakan sumberdaya yang dapat diperbaharui (renewable). Hal ini berarti jika sumberdaya ikan diambil sebagian, ikan yang tersisa memiliki kemampuan untuk memperbaharui dirinya dengan berkembang biak (Nikijuluw, 2002).

Sumberdaya ikan teri merupakan sumberdaya neritik, karena penyebarannya terutama adalah di perairan dekat pantai pada wilayah dimana terjadi proses penarikan masa air (upwelling). Ikan teri dapat membentuk biomasa yang besar dan merupakan jenis komoditas perikanan laut yang banyak memberi manfaat ekonomi bagi masyarakat nelayan di wilyah pesisir, sehinga teri banyak di tangkap karena mempunyai arti penting sebagai bahan makanan yang dapat di manfaatkan baik sebagai ikan 
segar maupun ikan kering (Nontji, 2000). Sebagai salah satu jenis ikan ekonomis penting, ikan teri dapat di temukan dalam jumlah yang besar di suatu perairan jika kondisi lingkungan perairan tersebut sesuai dengan kebutuhan hidupnya dan memiliki ketersediaan makanan yang memadai dan juga ikan teri merupakan salah satu jenis organisme penghuni perairan yang rentan terhadap perubahan lingkungan dan tingkat eksploitasi secara besar-besaran.

Eksploitasi ikan teri umumnya menggunakan alat tangkap bagan perahu, dimana alat tangkap ini memiliki tingkat produksinya tinggi dan sifatnya aktif. Secara umum, ketersediaan sumberdaya ikan teri sangat tergantung terhadap pertumbuhan, dimana ikan akan mengalami pertumbuhan secara terus menerus sepanjang hidupnya. Pertumbuhan berkaitan dengan masalah penambahan dalam besaran jumlah dan ukuran atau dimensi tingkat sel organ induvidu yang biasa di ukur dengan mengukur berat, panjang, umur, dan keseimbangan metobolik.

Mengingat pemanfaatannya dengan menggunakan alat tangkap yang sifatnya aktif dan tingkat produksi yang tinggi dan agar penangkapannya dapat berlangsung terus dan kelestariannya dapat tetap dipertahankan maka diperlukan upaya pengelolaan yang baik terhadap sumberdaya ikan teri untuk meminimalkan permasalahan penurunan stok populasi dimasa yang akan datang. Sebelum pengelolaan dilaksanakan, sehingga sebagai informasi awal kajian mengenai parameter dinamika populasi ikan teri perlu diketahui. Oleh karena itu, penelitian ini perlu dilakukan untuk mengetahui informasi parameter dinamika populasi ikan teri di perairan Laut Maluku yang didaratkan di Pasar Higienis Kota Ternate Provinsi Maluku Utara.

\subsection{Tujuan dan Manfaat Penelitian}

Penelitian ini bertujuan untuk mengkaji parameter dinamika populasi ikan teri yang didaratkan di Pasar Higienis Kota Ternate Provinsi Maluku Utara. Sedangkan penelitian ini dapat di gunakan sebagai suatu informasi tentang dinamika populasi ikan teri dalam pemanfaatan ikan teri secara berkelanjutan.

\section{METODE PENELITIAN}

\subsection{Waktu dan Tempat Penelitian}

Penelitian ini dilaksanakan selama bulan Januari sampai Maret 2019 di Laboratorium pengolahan hasil perikanan program studi Teknologi Hasil Perikanan dengan mengukur panjang dan berat ikan teri yang didaratkan di Pasar Higienis Kota Ternate.

\subsection{Alat dan Bahan}

Peralatan yang digunakan dalam penelitian meliputi meja ukur (mm), timbangan (gram), kamera digital, alat tulis menulis dan 1 unit komputer untuk analisis data dan pembuatan laporan penelitian, sedangkan bahan yang digunakan dalam penelitian ini adalah ikan teri untuk identifikasi dan data penelitian serta es batu untuk cool chain system.

\subsection{Analisis Data}

\subsubsection{Sebaran frekuensi panjang}

Sebaran frekuensi panjang yang telah di tentukan dalam selang kelas panjang yang sama, kemudian diplotkan dalam sebuah grafik. Pada grafik tersebut dapat di duga pergeseran sebaran kelas panjang setiap pengambilan contoh, yang menggambarkan jumlah kelompok umur (kohort) yang ada dalam perubahan posisi ukuran panjang kelompok umur yang sama

\subsubsection{Identifikasi kelompok}

Pendugaan kelompok umur ukuran dilakukan dengan menganalisis frekuensi panjag ikan teri. Data frekuensi di analisis dengan menggunakan salah satu metode yang terdapat dalam program FISAT II (FAO-ICLARM Stok assesment tool) yaitu metode NORMSEP (Normal separtion). Sebaran frekuensi panjang di kelompokan kedalam beberapa kelompok umur yang di asumsikan penyebaran normal, masing-masing di cirikan oleh rata-rata panjang dan di simpangan baku.

Menurut Boer (1996) jika $f_{1}$ adalah frekuensi ikan dalam kelas panjang ke $-I(i=1,2 \ldots . . \mathrm{N}) . \mu_{\mathrm{J}}$ adalah rata-rata panjang kelompok umur ke-j,$\breve{O}_{j}$ simpangan baku panjang kelompok umur ke-j dan $p_{j}$ adalah proporsi ikan dalam kelompok umur ke-j ( $j=1,2 \ldots G)$ Maka fungsi objektif yang di gunakan untuk menduga $\left\{\mu_{\mathrm{j}, ~} \mathrm{oj}_{\mathrm{j}}, \mathrm{p}_{\mathrm{j}}\right\}$ adalah fungsi kemungkinan maksimum (maximum likelihood function) : 
$\mathrm{L}=\sum_{1=1}^{N} F 1 \log \sum_{J=1}^{G} p j q u$ Sedangkan $\mathrm{q}_{\mathrm{ij}}=\frac{1}{G J \sqrt{2 \pi}} \mathrm{G}_{1}-\frac{1}{2}\left(\frac{X i-u j}{G J}\right)^{2}$ yang merupakan fungsi keepekatan sebaran normal dengan nilai tengah $\mathrm{u}_{\mathrm{j}}$ dan sipangan baku $\mathrm{O}_{\mathrm{j} .} X_{i}$ adalah titik tengahkelas panjang ke-

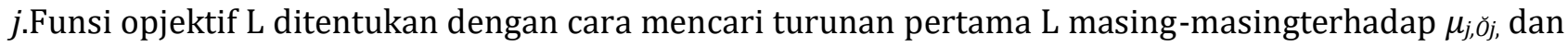

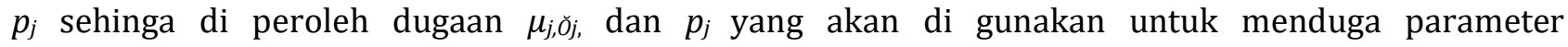
pertumbuhan.

\subsubsection{Hubungan panjang dan bobot}

Bobot dapat diangap sebagai fungsi dari panjang.Hubungan panjang dan berat hampir mengikuti hukum kubik yaitu bahwa berat ikan sebagai pankat tiga.Namun sebenarnya tidak demikian karna panjang dan berat ikan berbeda beda sehinga untuk menganalisis hubungan panjang dan berat ikan masing - masing spesies ikan digunakan rumus sebagai berikut (Effendie, 1997).

$$
\mathrm{W}=\alpha \mathrm{L}^{\beta}
$$

$\mathrm{W}$ adalah bobot (gram). L adalah panjang $(\mathrm{mm}), \alpha$ adalah intersep (perpotongan kurva hubungan panjang beratdangan sumbu y), $\beta$. adalah pendugaan pola pertumbuhan panjang berat. Nilai $\alpha$ dan $\beta$ diduga dari bentuk linier persamaan diatas yaitu :

$$
\log W=\log \alpha+\beta \log L
$$

Untuk mendapatkan parameter a dan b, digunakan analisis regresi dengan Log $\mathrm{W}$ sebagai y dan $\log \mathrm{L}$ sebagai $\mathrm{x}$,maka didapatkan persamaan regresi:

$$
\mathrm{yi}=\alpha_{\mathrm{i}}+\beta_{\mathrm{i}} \mathrm{x}_{\mathrm{i}}+\varepsilon \mathrm{i}, \hat{Y}_{i}=\mathrm{b}_{0}+\mathrm{b}_{\mathrm{i}} \mathrm{x}
$$

Konstanta $b$ diduga dangan $b_{1}$ dan konstanta a diduga dengan $b_{0}$ sedankan $b_{1}$ dan $b_{0}$ masingmasing dihitung dengan (Dowdy et al, 2004)

$$
\mathrm{Bi}=\frac{\sum_{i=1}^{n} x i y i-\frac{1}{n} \sum_{i=1}^{n} x i \sum_{i=1}^{n} y i}{\sum_{i=1}^{n} x i 2_{-} \frac{1}{n} \sum_{i=1}^{n} x i}
$$

Untuk menguji nilai $\beta_{1} \geq 3$ atau $\beta_{1} \leq 3$ digunakan uji-t,dengan hipotesis :

$\mathrm{H}_{0}: \beta_{1} \geq 3$, hubungan panjang dengan bobot adalah isometric.

$\mathrm{H}_{1}: \beta_{1} \leq 3$, hubungan panjang dengan bobot adalah allometrik.

$$
t_{\text {hitung }}=\frac{b_{1}-3}{s b_{1}}
$$

$\mathrm{S}_{\mathrm{b} 1}$ adalah simpangann baku dugaan $\mathrm{b}_{1}$ atau $\mathrm{b}$ yang dihitung dengan :

$$
\mathrm{S}_{\mathrm{b} 1}=\frac{s^{2}}{\sum x D^{2} \frac{1}{n\left(\sum x i\right)^{2}}}
$$

Sedangkan $s^{2}$ adalah kuadrat tengah sisa sebagai penduga $o^{2}$, yang dapat dihitung dengan

$$
\underline{\left[\sum y_{i}^{2}-\frac{1}{n} 9\left(\sum y_{i}^{2}\right)\right]-\left[\mathrm{b}_{1} \mathrm{i}\left\{\sum x_{\mathrm{i}} \mathrm{y}_{\mathrm{i}}^{-} \frac{1}{n} \sum \quad x \mathrm{i} \sum y_{\mathrm{i}}\right\}\right]}
$$

Pada selang kepercayaan $95 \%$ bandingkan nilai $t_{\text {hitung }}$ dengan niilai $t_{\text {tabel }}$ kemudian keputusan yang diambil untuk menggetahui pola pertumbuhan ikan yaitu : $t_{\text {hitung }}>t_{\text {tabel }}$ : tolak hopotesis nol $\left(\mathrm{H}_{0}\right)$, 
$t_{\text {hitung }}<t_{\text {tabel }}$ : gagal tolak hipotesis nol $\left(\mathrm{H}_{0}\right)$. Allometrik dibagi menjadi dua yaitu allometrik positif $(b>3)$ dimana pertambahan berat ikan lebih cepat dari pada pertambahan panjang dan allomertik negative $(b<3)$ dimana pertambahan panjang ikan lebih ccepat dibandingkan dengan pertambahan berat.

\subsubsection{Plot Ford Walford ( $L_{\infty} K$, dan $\left.t_{0}\right)$}

Pendugaan nilai koefesien bertambah (K) dan Lœ dilakukan dengan menggunakan metode plot ford- walford, sedangkan nilai dengan $\mathrm{t}_{0}$ ( umur teoritis ikan pada saat panjang sama dengan nol) di peroleh melalui persamaan pauly (1984) $\log \left(-\mathrm{t}_{0}\right)=3.3922-0.2752(\mathrm{~L} \infty)-1,038(\log \mathrm{K})$

Ketiga nilai dugaan parameter tersebut di masukan ke model pertumbuhan Von Bertalanffy :

$$
\mathrm{L}_{\mathrm{t}}=\mathrm{L} \infty\left[1-e^{-\mathrm{k}\left(\mathrm{t}-\mathrm{t}_{0}\right)}\right]
$$

$\mathrm{L}_{\mathrm{t}}$ adalah panjang ikan pada saat umur t (satuan waktu), L $\infty$ adalah panjang maksimum secara teoritis (panjang asimotik). $\mathrm{K}$ adalah koefesien pertumbuhan (per satuan waktu ), dan $\mathrm{t}_{0}$ adalah umur pada saat panjang sama nol. Untuk $t$ sama dengan $t+1$, persamaan menjadi :

$$
\mathrm{L}_{\mathrm{t}+1}=\mathrm{L} \infty 1-\mathrm{e}^{-\mathrm{k}\left(\mathrm{t}-\mathrm{t}_{0}\right)} \text { sehingga } \mathrm{L}_{\mathrm{t}+1}-\mathrm{L}_{\mathrm{t}}=e^{-\mathrm{K}\left(\mathrm{t}-\mathrm{t}_{0}\right)}\left[1-\mathrm{e}^{-\mathrm{K}}\right]
$$

Dengan mendistribusikan persamaan diatas, di peroleh

$$
\mathrm{L}_{\mathrm{t}}+1-\mathrm{L}_{\mathrm{t}}=\left[\mathrm{L} \infty-\mathrm{L}_{\mathrm{t}}\right]+\left[1-\mathrm{e}^{-\mathrm{K}}\right] \text { atau } \mathrm{L}_{\mathrm{t}}+1=\mathrm{L} \infty\left[1-\mathrm{e}^{-\mathrm{K}}\right]+\mathrm{L}_{\mathrm{t}} \mathrm{e}^{-\mathrm{K}}
$$

$\mathrm{L}_{\mathrm{t}}$ dan $\mathrm{L}_{\mathrm{t}=1}$ merupakan panjang ikan pada saat $\mathrm{t}$ dan saat $\mathrm{t}+1$ yang merupakan panjang ikan yang di pisahkan oleh interval waktu yang konsisten (1=tahun, bulan atau minggu) (pauly 1984). Persamaan (15) dapat di duga dengan persamaan regresi linear $y=b_{0}+b_{1} X$, jika $L_{t}$ sebagai absis ( $x$ ) diplotkan terhadap $\mathrm{L}_{\mathrm{t}+1}$ sebagai ordinat (y) sehingga terbentuk kemiringan (slope) sama dengan $\mathrm{e}^{-\mathrm{K}} \mathrm{dan}$ titik potong dengan absis sama dengan $\mathrm{L} \infty\left[1-\mathrm{e}^{-\mathrm{K}}\right]$ dengan demikian, nilai $\mathrm{K}$ dan Lo diperoleh dengan $\mathrm{K}=-1 \mathrm{n}(\mathrm{b})$.

$$
\mathrm{L} \infty=\frac{a}{(1-b)}
$$

\subsubsection{Moralitas dan laju Eksploitasi}

Laju mortalitas total (Z) Diduga berdasarkan persamaan kurva hasil tangkapan kumulatif berdasarkan data komposisi panjang (Metode Jones dan Van Zalinge) (Sparre and Venema 1999).

$$
\operatorname{Ln} C(\mathrm{~L}, \mathrm{~L} \infty)=+\frac{z}{k} \operatorname{In}(\mathrm{L} \infty-\mathrm{L})
$$

$\mathrm{Z}$ adalah laju mortalitas alami; K adalah koefesien pertumbuhan. Nilai Z di dapatkan dari hasil perhitungan dengan metode Jones anda Van Zalinge yang di peroleh melalui bantuan program mortality estimation yang terintegrasi dalam program software FISAT II (FAO-ICLARM Stok assessment tool).

Untuk laju mortalitas alami (M) Di duga dengan menggunakan rumus empiris paully (1980) in Sparred an Venema (1999) sebagai berikut :

$$
\text { Ln } \mathrm{M}=-0.0152-0.2791 \mathrm{n} \mathrm{L} \infty+06541 \mathrm{n} \mathrm{K}+0.463 \ln \mathrm{T}
$$

M adalah mortalitas alami, Lo adalah anjangasimotik pada persamaan pertumbuhan Von Bartalanfffy, $\mathrm{K}$ adalah koefesien pertumbuhan pada persamaan pertumbuhan von Bartalanffy, $\mathrm{T}$ adalah rata-rata suhu permukaan air $\left({ }^{\circ} \mathrm{C}\right)$. Laju mortalitas penangkapan (F) di tentukan : $\mathrm{F}=\mathrm{Z}-\mathrm{M}$ dan Laju eksploitasi (E) di tentukan dengan membandingkan laju mortalitas penangkapan (F) dengan laju mortalitas total (Z) (Pauly 1984) :

$$
\mathrm{E}=\frac{F}{F+M}=\frac{F}{Z}
$$

\section{HASIL DAN PEMBAHASAN}

\subsection{Produksi Ikan Teri}

Tahun 2019 produksi ikan teri yang didaratkan di pasar Higienis Kota Ternate sebanyak 21,760.91 kg dan 90,0 \% produksi tersebut dihasilkan oleh alat tangkap bagan perahu. Ikan teri merupakan ikan target utama bagi perikanan bagan perahu selama penelitian, dimana didapat bahwa 
produksi ikan teri cenderung berfluktuatif. Rata-rata produksi ikan teri yang diambil dari bagan perahu selama bulan Januari sampai Maret 2019 dapat dilihat pada Gambar 1.

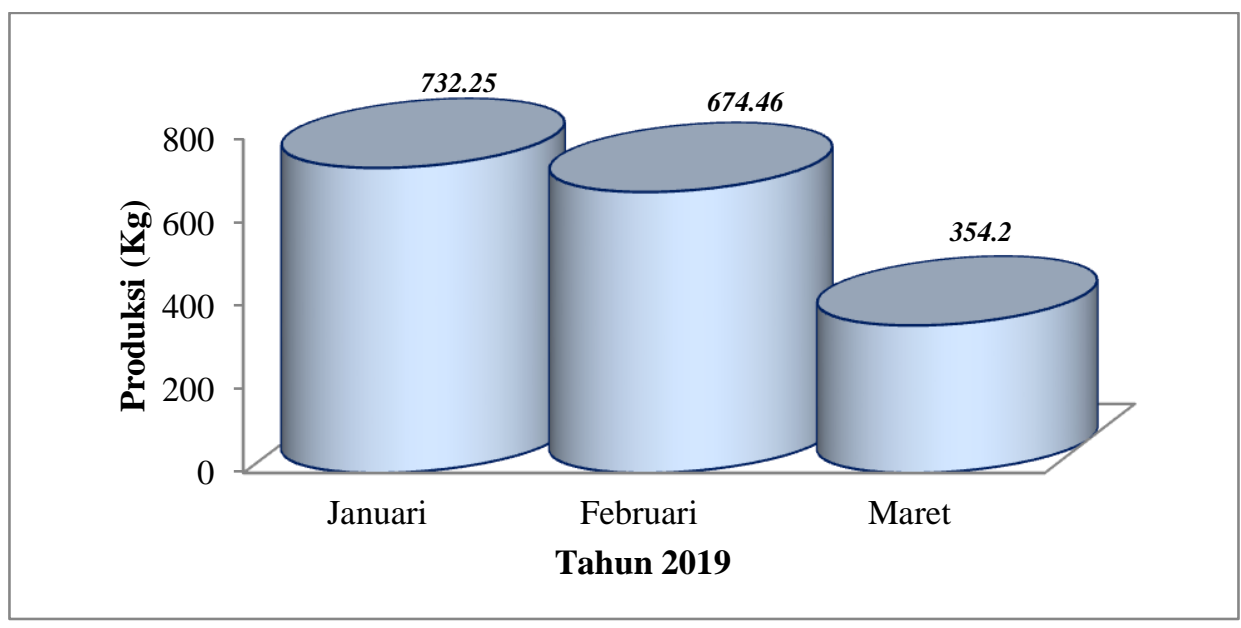

Gambar 1. Produksi Ikan Teri yang didaratkan di Pasar Higienis 2019

\subsection{Parameter Populasi}

\subsubsection{Kelompok Umur}

Jumlah sampel ikan teri yang diperoleh selama penelitian adalah 829 ekor dengan kisaran panjang total 28,0 - 78,0 mm. Ikan teri (Sthelophorus $\mathrm{sp}$ ) dikelompokan berdasarkan kelas ukuran kemudian dihitung frekuensi menurut kelompok umur. Dari kelas ukuran yang ada diperoleh frekuensi panjang dengan dua kelompok umur sehingga analisis hanya dapat dilakukan dengan program FISAT II. Berdasarkan hasil analisis Bhattacharya (Sparre et al,1999) dengan menggunakan hasil pemetaan selisih logaritma natural frekuensi teoritis terhadap nilai tengah kelas diperoleh dua kelompok umur pada ikan teri.

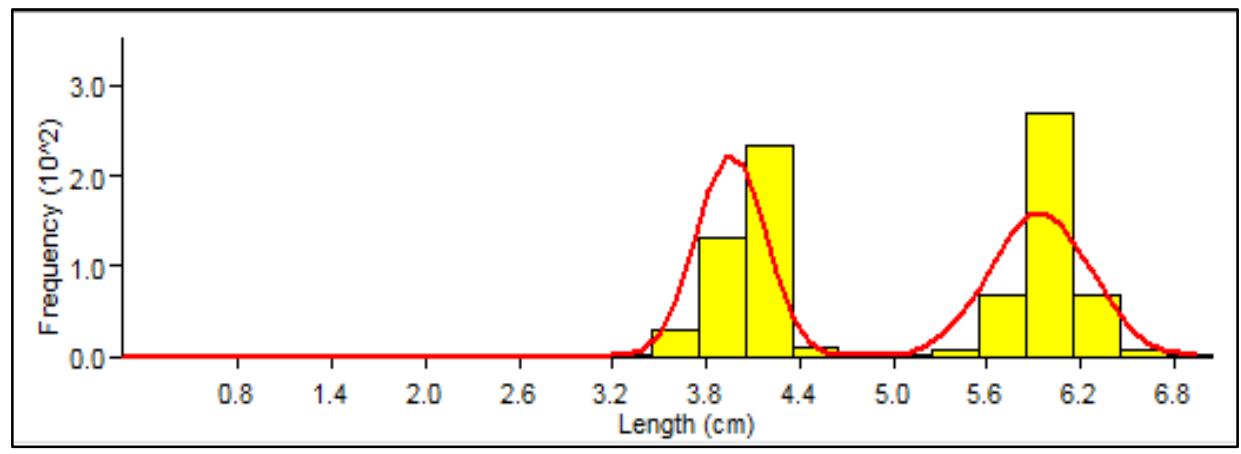

Gambar 2. Pemetaan nilai tengah kelas dengan selisih logaritma natural frekuensi kumulatif ikan Teri pada setiap kelompok umur dengan menggunakan program FISAT II

Hasil penelitian penelitian Fauziyah et al. (2012) di Muara Sungsang pada bulan Mei 2012 menjelaskan bahwa ukuran dominan ikan teri yang tertangkap antara 50-70 mm. Penelitian ikan teri di Perairan Kabupaten Pemalang yang dilakukan oleh Dewanti et al. (2014) menyebutkan bahwa pada bulan November modus sebaran frekuensi panjang berada pada selang kelas 53-56 mm dan pada bulan Desember modus sebaran frekuensi panjang berada pada selang kelas 57-60 mm. Bila dibandingkan dengan hasil penelitian ini, diperoleh hasil yang berbeda baik dari ukuran terkecil maupun ukuran terbesar. Perbedaan dalam Hal ini diduga karena disebabkan oleh faktor penangkapan dan faktor lingkungan yang ikut mempengaruhi hasil tangkapan ikan teri.

Dari hasil penelitian di atas, maka dilakukan pemetaan logaritma panjang total terhadap nilai tengah kelas diperoleh 2 panjang rata - rata dengan ukuran panjang masing - masing $40 \mathrm{~mm}$, dan 60 $\mathrm{mm}$. Hubungan antara kisaran panjang, umur relatif dengan panjang rata-rata dari ikan teri yang didaratkan di Pasar Higienis dapat dilihat pada tabel 1, sedangkan grafik pemetaan selisih logaritma natural frekuensi teoritis dengan nilai tengah kelas dapat dilihat pada Gambar 3. 
Tabel 1. Hubungan kisaran panjang, panjang rata-rata dan umur relatif pada ikan teri yang di daratkan di Pasar Higienis.

\begin{tabular}{ccc}
\hline $\begin{array}{c}\text { Umur Relatif } \\
\text { (Tahun) }\end{array}$ & Kisaran Panjang (mm) & Panjang rata-rata \\
\hline I & $32,5-52.5$ & 40 \\
II & $52.5-80,5$ & 60 \\
\hline
\end{tabular}

\subsubsection{Pertumbuhan}

Hasil analisis menggunakan metode Ford - Walford (Sparre et al. 1999) diperoleh nilai panjang asimptot (L) Ikan teri yang didaratkan di Pasar Higienis adalah 71,9 mm, dengan koefisien laju pertumbuhan $(\mathrm{K})$ adalah 0.26 per bulan. Sedangkan nilai $\mathrm{t}_{0}$ diperoleh dengan menggunakan rumus Pauly (1980) yaitu -0.99. Berdasarkan nilai $\mathrm{L} \infty, \mathrm{K}$, dan to yang diperoleh dengan menggunakan persamaan Von Bertalanffy didapatkan persamaan pertumbuhan ikan teri di Perairan Laut Ternate adalah $\mathrm{Lt}=71,9\left(1-\exp ^{0,26(t+0.99)}\right)$. Dari persamaan pertumbuhan diatas maka dapat diketahui panjang ikan teri dari berbagai umur relatif, sehingga dapat dihitung pertambahan panjang ikan teri untuk setiap tahunnya hingga mencapai panjang asimptotnya.

Berdasarkan hasil penelitian seperti yang terlihat pada kurva pertumbuhan tampak pada gambar 3 terlihat bahwa disaat umur muda pertumbuhan ikan teri sangatlah cepat sama halnya dengan pendapat (Azis,1989) mengatakan bahwa pertumbuhan panjang ikan teri yang cepat terjadi pada umur muda dan semakin lambat seiring dengan bertambahnya umur sampai mencapai panjang asimptot dimana ikan bertambah panjang lagi. Selain itu juga pertumbuhan cepat bagi ikan yang berumur muda terjadi karena energi yang didapatkan dari makanan sebagian besar digunakan untuk pertumbuhan. Pada ikan tua energi yang didapatkan dari makanan tidak lagi digunakan untuk pertumbuhannya, tetapi hanya digunakan untuk mempertahankan dirinya dan mengganti sel-sel yang rusak (Jalil dan Mallawa, 2001)

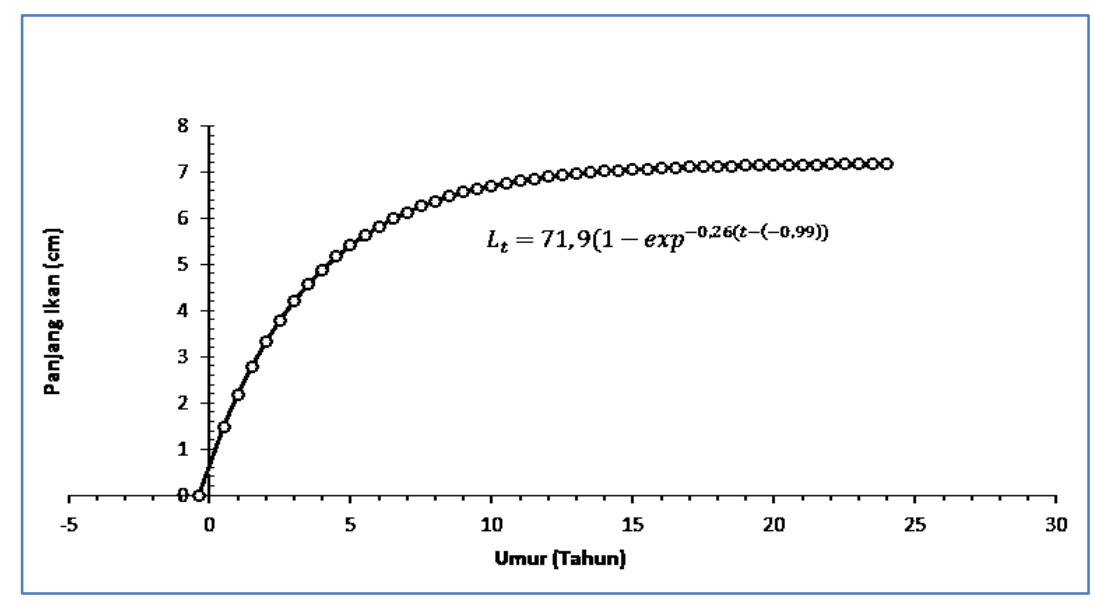

Gambar 3. Kurva pertumbuhan ikan teri.

Ikan teri yang didaratkan di Pasar Higienis mempunyai laju pertumbuhan yang cepat yaitu 0.26 per bulan dan nilai panjang maksimum ( $\mathrm{L}_{\infty}$ ) ikan teri sebesar $71.9 \mathrm{~mm}$ sehingga memerlukan waktu yang relatif cepat untuk mencapai panjang maksimumnya. Hal ini sesuai dengan pernyataan Sparre et al (1999) bahwa ikan yang mempunyai nilai koefisien laju pertumbuhan yang tinggi memerlukan waktu yang singkat untuk mencapai panjang asimptot atau panjang maksimumnya dan ikan yang mempunyai nilai koefisien laju pertumbuhan yang rendah memerlukan waktu yang lama untuk mencapai panjang asimptotnya.

\subsubsection{Mortalitas}

Pendugaan laju mortalitas total (Z) dianalisis dengan menggunakan metode Beverton dan Holt (Sparre,et al 1999). Untuk ikan teri di peroleh nilai dugaan mortalitas total (Z) sebesar 1,33 per tahun, sedangkan nilai mortalitas alami (M) dianalisa dengan menggunakan rumus Empiris Pauly (1980) dengan memasukkan nilai $\mathrm{K}=0.26$ per tahun, $\mathrm{L}_{\infty}=71,9 \mathrm{~mm}$ dan rata-rata suhu perairan $28^{\circ} \mathrm{C}$. Dengan demikian diperoleh nilai dugaan mortalitas alami $(\mathrm{M})=1,12$ sedangkan nilai laju mortalitas penangkapan (F) diperoleh dengan mengurangkan nilai $\mathrm{Z}$ terhadap $\mathrm{M}$ sehingga diperoleh nilai dugaan 
$F=0,21$ per tahun. Nilai laju eksploitasi (E) diperoleh dengan membagi nilai $F$ terhadap nilai $Z$ sehingga diperoleh $\mathrm{E}=0,16$ per tahun.

Tabe 2. Nilai dugaan mortalitas dan laju eksploitasi ikan teri yang didaratkan di Pasar Higienis.

\begin{tabular}{lc}
\hline \multicolumn{1}{c}{ Parameter populasi } & Nilai Dugaan (per tahun) \\
\hline Mortalitas Total (Z) & 1,33 \\
Mortalitas Alami (M) & 1,12 \\
Mortalitas Penangkapan (F) & 0,21 \\
Laju Eksploitasi (E) & 0,16 \\
\hline
\end{tabular}

Berdasarkan Tabel 2, dapat dilihat nilai mortalitas alami (M) lebih besar dari mortalitas penangkapan (F), hal ini menunjukan bahwa kematian ikan teri di Pasar Higienis lebih banyak tidak disebabkan oleh faktor penangkapan, tetapi oleh kematian secara alami sehingga stok populasi dapat stabil secara cepat. Oleh karena itu perlu dilakukan upaya yang lebih besar lagi melalui peningkatan effort agar sumberdaya hayati ikan teri kedepannya akan dapat termanfaatakan secara maksimal sampai pada $80 \%$ dari MSY.

\subsubsection{Laju Eksploitasi dan Hasil Rekruitmen}

Pendugaan stok yield per rekruitment merupakan salah satu model yang bisa digunakan sebagai dasar strategi pengelolaan perikanan. Analisa ini diperlukan dalam pengelolaan sumberdaya perikanan, karena model ini memberikan gambaran mengenai pengaruh-pengaruh jangka pendek dan jangka panjang dari tindakan-tindakan yang berbeda (Gulland, 1983). Nilai dugaan Y/R dianalisi dengan metode Beverton dan holt dalam Sparre et al (1999) dengan memasukan nilai-nilai yang terdapat pada Tabel 3.

Tabel 3. Nilai dugaan parameter yang digunakan sebagai masukkan pada analisis Yield Per Recruitment ikan teri.

\begin{tabular}{lc}
\hline \multicolumn{1}{c}{ Parameter populasi } & $\begin{array}{c}\text { Nilai Dugaan (per } \\
\text { tahun) }\end{array}$ \\
\hline Koefisien Laju Pertumbuhan (K) & 0.26 \\
Panjang Asimptot ( Lo) & $71,9 \mathrm{~mm}$ \\
Mortalitas Total (Z) & 1.33 \\
Mortalitas Alami (M) & 1,12 \\
Mortalitas Penangkapan (F) & 0.21 \\
Laju Eksploitasi (E) & 0.16 \\
\hline
\end{tabular}

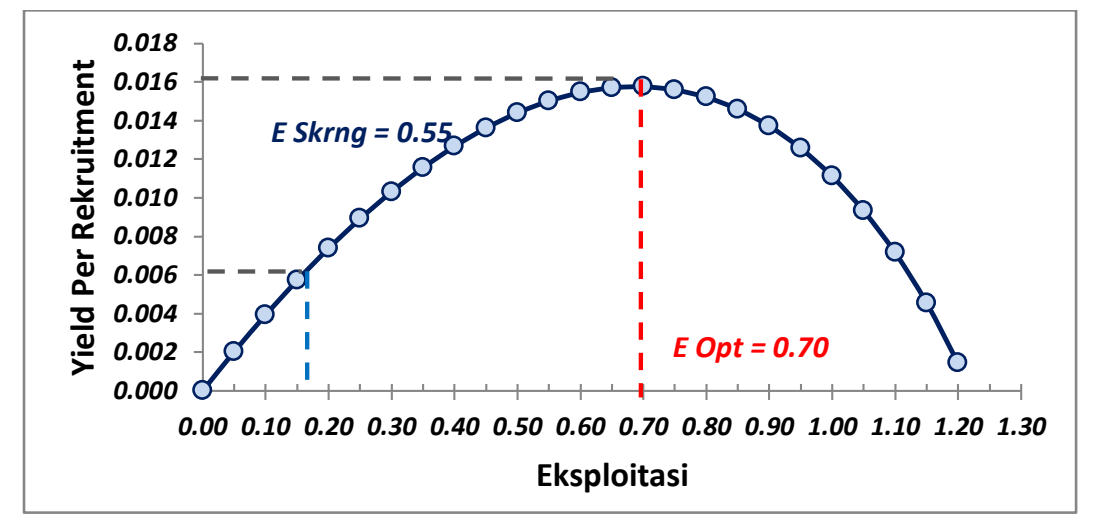

Gambar 4. Kurva hubungan Yield per Rekruitment (Y/R) terhadap nilai laju eksploitasi (E) ikan teri.

Berdasarkan hasil analisis pada Tabel 3, maka dapat diketahui bahwa nilai dugaan Y/R sebesar 0.006 gram/recruit. Ini berarti bahwa dalam setiap recruitmen yang terjadi terdapat 0.79 gram yang diambil sebagai hasil tangkapan. Nilai $E$ yang diperoleh saat ini adalah 0.70 dengan $Y / R=0.006$ gram/recruitmen, nilai E opt $=0.70$ dan E skrg $=0.16$ dapat dilihat pada kurva (Gambar 4). Seperti yang terlihat pada Gambar 4, bahwa nilai E sekarang adalah 0.16 dan E optimumnya adalah 0.70, ini berarti bahwa tingkat eksploitasi ikan teri yang didaratkan di Pasar Higienis masih relatif kecil dan 
belum mencapai nilai yang optimal sehingga perlu di tingkatkan jumlah effor untuk memanfaatkan sumberdaya ikan tersebut agar tidak mati secara percuma.

\subsubsection{Hubungan Panjang Berat}

Sifat pertumbuhan pada studi ini menjelaskan tentang hubungan panjang bobot dan faktor kondisi. Hubungan panjang berat menggambarkan hubungan secara matematik antara dua variabel serta memberikan suatu petunjuk keadaan ikan baik itu dari kondisi ikan itu sendiri dan kondisi luar yang berhubungan dengan ikan tersebut. Pertumbuhan adalah pertambahan ukuran panjang atau berat dalam suatu waktu (Effendie 1997). Analisa hubungan panjang berat dapat digunakan untuk mempelajari pertumbuhan. Berdasarkan Effendie (1997) terdapat dua faktor yang berpengaruh dalam pertumbuhan yaitu faktor dalam dan luar. Hasil analisis hubungan antara panjang dan bobot ikan teri menunjukkan bahwa pertumbuhan ikan teri mengikuti persamaan $\mathrm{W}=0.1633 \mathrm{~L}^{0.3912}(\mathrm{~N}=821) ; \mathrm{r}^{2}=$ 0,915) (Gambar 5).

Setelah dilakukan uji t dengan tingkat kepercayaan 95\% $(\alpha=0,05)$, dengan t hitung 4.4615 dan $t$ tabel adalah 1.9732, didapatkan pola pertumbuhan ikan teri bersifat allometrik positif, yang berarti pertambahan berat ikan teri lebih cepat dibandingkan pertambahan panjangnya. Hubungan antara panjang dengan bobot dapat memberikan informasi tentang kondisi biota, dimana berat biota akan meningkat sehubungan dengan meningkatnya volume (Jenningsetal.,2001).. Penelitian Dewanti et al. (2014) menyatakan pola pertumbuhan Stolephorus devisi di Kabupaten Pemalang memiliki pola pertumbuhan alometrik positif dengan nilai a sebesar 0,0000047 dan nilai b sebesar 3,125. Rao (1988) menyatakan bahwa Stolephorus devisi memiliki nilai $b=3,013$ dan penelitian (Yuanda et al., 2015) di Belawan menghasilkan pola pertumbuhan alometrik negatif dengan nilai $a=0,007$ dan nilai $b$ $=2,975$. Hasil yang serupa pada penelitian Nair et al. (2015) di Pantai Kerala menunjukkan nilai $\mathrm{a}=$ 0,00756 dan $b=2,99$ untuk stolephorus commersonii betina, sedangkan ikan jantan memberikan nilai $\mathrm{a}=0,0070$ dan $\mathrm{b}=3,16$. Perbedaan nilai koefisien $\mathrm{b}$ diduga karena ketersediaan makanan, perbedaan jenis kelamin, kematangan gonad, lokasi dan kondisi kualitas perairan pada saat pengambilan contoh. Perbedaan pola pertumbuhan dipengaruhi oleh beberapa faktor internal dan eksternal. Faktor internal yang mempengaruhi pola pertumbuhan adalah genetik dan perkembanan gonad sedangkan faktor eksternal adalah lingkungan dan ketersediaan makanan (Effendie, 2002). Pola pertumbuhan juga dipengaruhi oleh tingkah laku ikan yang bergerak aktif dan melakukan ruaya (Utami et al., 2014).

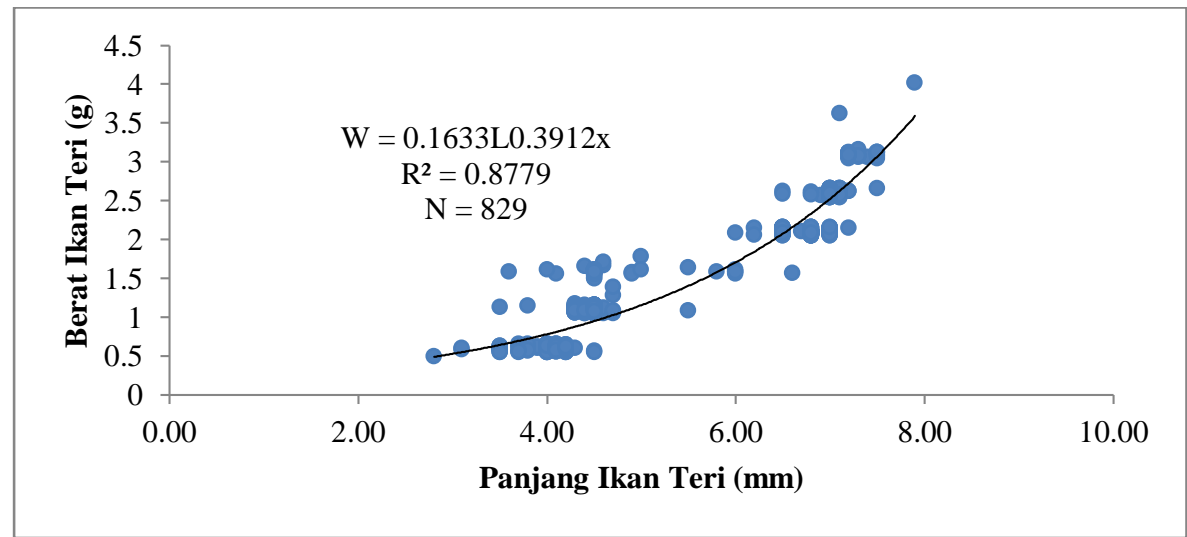

Gambar 5. Gambar Hubungan Panjang - Bobot Ikan Teri

\section{PENUTUP}

Sumberdaya ikan teri yang didaratkan di Pasar Higienis Kota Ternate memiliki parameter populasi yang masih stabil diantaranya panjang maksimum $(\mathrm{L} \infty)$ adalah $71,9 \mathrm{~mm}$ dengan koefisien pertumbuhan (k) 0,26 per bulan, nilai t0 $-0,99$, nilai mortalitas total, alami, dan penangkapan masingmasing adalah 1,$33 ; 1,12$ dan 0,21 dan tingkat eksploitasi yang masih sangat rendah dengan hubungan panjang bobot bersifat alometrik positif. Tingkat pemanfaatan sumber daya ikan teri yang didaratkan di Pasar Higienis masih rendah, sehingga perlu penambahan upaya untuk meningkatkan produksi secara maksimal dengan penambahan jumlah effort. 


\section{DAFTAR PUSTAKA}

Baskoro M S dan Suherman A. 2007. Teknologi Penangkapan Ikan dengan Cahaya. Undip Press. Semarang

Beverton RJH \& Holt SJ. 1957. On the dynamics of exploited fish population. Her Majessty's Statinery Office. London. 533 p.Hutomo M, Burhanuddin, Djamali A, \& S. Matosewojo.1987. Sumberdaya ikan teri di Indonesia. Pusat Penelitian dan pengembangan Oseanogologi. LIPI. Jakarta. $80 \mathrm{hlm}$.

BPPI. 2007. Klasifikasi Alat Penangkapan Ikan Indonesia. BPPI Semarang. 95 hal.

[DKP] Dinas Kelautan dan Perikanan Provinsi Maluku Utara., 2016. Statistik Perikanan Tangkap Provinsi Maluku Utara. Prov. Maluku Utara.

Dewanti, R.O.N., A. Ghofar, dan S.W. Saputra. 2014. Beberapa aspek biologi ikan teri (Stolephorus devisi) yang tertangkap payang di Perairan Kabupaten Pemalang. Diponegoro J. of Maquares, 3(4):102-111.

Dowdy S, Wearden S, dan Dildo D. 2004. Statistic for research. John Willey \& Sons, Inc. Publication. Amerika. 627 p.

EffendiSe MI. 1997. Biologi perikanan. Yayasan Pustaka Nusantara. Yogyakarta. $163 \mathrm{hlm}$.

Luasunaung. A. 2011. Analisa Musim Penangkapan Teri (Stolephorus spp) di Teluk Dodinga, Kabupaten Halmahera Barat. Jurnal Perikanan dan Kelautan Tropis. Vol VII-1. Fakultas Perikanan dan Ilmu Kelautan Universitas Samratulangi, Manado

Mughnia. 2009. Hubungan Hasil Tangkapan Dengan Kelimpahan Plankton Pada Bagan Perahu Di Perairan Teluk Toniku Kabupaten Halmahera Barat Provinsi Maluku Utara. Skripsi. Program Studi Pemanfaatan Sumberdaya Perairan. Fakultas Perikanan dan Kelautan Universitas Khairun. Ternate

Nikijuluw VPH. 2002. Rezim pengelolaan sumberdaya perikanan. Pustaka Cidesindo. Jakarta Selatan. $254 \mathrm{hlm}$.

Nair, P.G., S. Joseph, and V.N. Pillai. 2015. Length-weinght relationship and relative condition factor of Stolephorus commersonii (Lacepede, 1803) exploited along Kerala coast. J. Marine Biological Association of India. 57(2):27-31. Doi: 10.6024/ jmbai.2015.57.2.01856-04

Nontji A. 2005. Laut nusantara. Djambatan. Jakarta. $372 \mathrm{hlm}$.

Pauly D. 1984. Fish population dynamics in tropical waters: A Manual for Use with Programmable Calculators. Manila: ICLARM. 325 p.

Rao, G.S. 1988. Some aspects of biology of Stolephorus bataviensis Hardenberg, from mangalore area, Dakshina Kannada. J. of the Marine Biological Association of India, 30(1\&2): 107- 113.

Saanin H. 1968. Taksonomi dan Kunci Identifikasi Ikan 1 dan 2. Binacipta. Bogor. $508 \mathrm{hlm}$.

Supriyadi. 2008. Dampak perikanan payang terhadap kelestarian stok ikan teri nasi (Stolephorus spp.) di Perairan Kabupaten Cirebon dan alternative pengelolaannya [skripsi]. Departemen Manajemen Sumberdaya Perairan, Fakultas Perikanan dan Ilmu Kelautan, Institut Pertanian Bogor. Bogor. $106 \mathrm{hlm}$.

Sudirman dan Nessa. 2011. Perikanan Bagan dan Aspek Pengelolaannya. UMM Press. Malang.

Sudirman dan Mallawa, A. 2004. Teknik Penangkapan Ikan. Rineka Cipta. Jakarta.

Sparre P \& Venema SC. 1999. Introduksi pengkajian stok ikan tropis buku-i manual (Edisi Terjemahan). Kerjasama Organisasi Pangan, Perserikatan Bangsa-Bangsa dengan Pusat Penelitian dan Pengembangan Perikanan, Badan Penelitian dan Pengembangan Pertanian. Jakarta. $438 \mathrm{hlm}$.

Utami, M.N.F., S. Redjeki, dan E. Supriyantini. 2014. Komposisi isi lambung ikan kembung lelaki (Rastrelliger kanagurta) di Rembang. J. of Marine Research, 2(3):99-106.

Yuanda, D., M.B. Mulya, dan A. Muhtadi. 2015. Pertumbuhan dan laju eksploitasi ikan teri pekto (Stolephorus waitei) di Perairan Belawan Kota Medan Sumatera utara. J. Aquacoastmarine. 15(1):120-130. 